ORIGINAL ARTICLE

\title{
Vitamin C supplementation in very preterm infants: a randomised controlled trial
}

\author{
B A Darlow, H Buss, F McGill, L Fletcher, P Graham, C C Winterbourn
}

Arch Dis Child Fetal Neonatal Ed 2005;90:F117-F122. doi: 10.1136/adc.2004.056440

See end of article for authors' affiliations .....................

Correspondence to: Professor Darlow, Department of Paediatrics, Christchurch School of Medicine and Health Sciences, PO Box 4345, Christchurch, New Zealand; brian.darlow@ chmeds.ac.nz

Accepted 7 October 2004
Objective: To determine whether regulating vitamin $C$ (ascorbic acid: $A A$ ) intake to achieve higher or lower plasma concentrations was associated with improved clinical outcome.

Design: A double blind, randomised controlled trial.

Setting: Neonatal intensive care unit at Christchurch Women's Hospital.

Patients: Infants with birth weight $<1500 \mathrm{~g}$ or gestation $<32$ weeks, admitted to the unit within 48 hours of birth.

Intervention: Infants were randomised to one of three protocols with regard to AA supplementation for the first 28 days of life: group LL received low supplementation throughout; group LH received low until day 10 and then high: group $\mathrm{HH}$ received high throughout.

Main outcome measures: Primary outcome measures were oxygen requirement at 28 days and 36 weeks postmenstrual age, total days supplemental oxygen, and retinopathy of prematurity. AA concentrations were measured at study entry (day 2), and days 10, 21, and 28.

Results: A total of 119 infants were enrolled over 24 months (mean gestation 28.4 weeks; birth weight $1161 \mathrm{~g})$. Six infants died, and these had significantly higher AA concentrations before randomisation than surviving infants $(116 \mu \mathrm{mol} / \mathrm{l}$ (95\% confidence interval 90 to 142$) \vee 51 \mu \mathrm{mol} / \mathrm{l}(45$ to 58$), \mathrm{p}<0.0001)$. There were no significant differences in primary outcomes between the groups. However, the proportion of surviving infants with an oxygen requirement at 36 weeks postmenstrual age in group $\mathrm{HH}(19 \%)$ was half that in group LL (41\%) ( $p=0.06)$.

Conclusions: In a randomised controlled trial, no significant benefits or harmful effects were associated with treatment allocation to higher or lower AA supplementation throughout the first 28 days of life.
$\mathrm{V}$ itamin C (ascorbic acid: AA) is an important aqueous phase antioxidant in cells and plasma. ${ }^{12}$ However, at least in vitro, AA also has pro-oxidant activity, principally by reducing ferric iron to the ferrous form, which converts hydrogen peroxide into the more toxic hydroxyl radical (Fenton reaction). ${ }^{3}$ AA has a number of important metabolic functions and is actively transported across the placenta. ${ }^{5}$ AA concentrations in cord plasma are higher than the mother's and, in term infants, plasma concentrations fall considerably over the first 24 hours of life. ${ }^{6}$ Preterm infants generally have higher cord AA concentrations than term infants, ${ }^{78}$ and concentrations then decline over a few days. ${ }^{8}$

Most preterm infants receive AA as part of a multivitamin supplement, but there are few data on which to base optimum concentrations. ${ }^{9}$ One recommendation derives from the concentrations found in healthy breast fed term infants, with an adequate AA concentration stated as $>34 \mu \mathrm{mol} / \mathrm{l}^{10}$ Breast milk contains 3.5-5.5 mg AA per $100 \mathrm{ml},{ }^{11-13}$ so that an average infant having $150 \mathrm{ml} / \mathrm{kg} /$ day of milk will receive $5.2-$ $8 \mathrm{mg} / \mathrm{kg} /$ day. The alternative view is that preterm infants should receive higher doses of AA, $25-31 \mathrm{mg} / \mathrm{kg} / \mathrm{day}$, to achieve concentrations closer to those in utero in the third trimester. ${ }^{10}$

There have been few studies of the relation between AA concentration and morbidity in very preterm infants. Silvers et al $^{14}$ reported that plasma AA concentrations within 2 hours of birth were significantly higher in infants who died compared with survivors. These researchers also observed that higher AA concentrations on day 2 were associated with a greater risk of developing bronchopulmonary dysplasia. ${ }^{15}$ In contrast, Moison et a ${ }^{16}$ reported lower plasma AA concentrations on day 10 in preterm infants who developed bronchopulmonary dysplasia compared with those who did not. In a pilot observational study of very low birthweight infants (birth weight $<1500 \mathrm{~g}$ ), we found an increased risk of retinopathy of prematurity (ROP) with higher plasma AA concentrations at day 7 and an increased risk of bronchopulmonary dysplasia with lower concentrations at 28 days. $^{17}$

In this study, we aimed to determine in a randomised, controlled trial whether regulating AA intake to achieve higher or lower plasma concentrations is associated with improved clinical outcome. We hypothesised that maintaining a lower plasma AA concentration (target 35-50 $\mu \mathrm{mol} / \mathrm{l}$ ) in the first week of life and a higher concentration (target $90 \mu \mathrm{mol} / \mathrm{l}$ ) in weeks $3-4$ would be accompanied by least morbidity.

\section{METHODS}

Infants with birth weight $<1500 \mathrm{~g}$ or gestation $<32$ weeks admitted to the neonatal intensive care unit at Christchurch Women's Hospital were eligible for study. Signed, informed parental consent was obtained within 72 hours of birth. The study was approved by the Canterbury Ethics Committee.

This was a randomised, double blinded, placebo controlled trial. Infants were randomised by pharmacy through sealed envelopes to one of three protocols for AA supplementation for the first 28 days of life: group LL received low AA supplements throughout; group LH received low AA supplements until day 10, then high supplements until day 28; group $\mathrm{HH}$ received high AA supplements throughout.

Abbreviations: $A A$, ascorbic acid; $C R I B$, clinical risk index for babies; $R O P$, retinopathy of prematurity 
Table 1 Comparison of vitamin doses (per kg per day) received by preterm infants given one of two standard multivitamin regimens during parenteral nutrition

\begin{tabular}{|c|c|c|c|c|c|c|c|c|c|c|c|c|c|}
\hline & C (mg) & $A(m g)$ & $D(\mu g)$ & $B_{1}(\mathrm{mg})$ & $B_{2}$ (mg) & $B_{6}$ (mg) & $\begin{array}{l}\text { Niacin } \\
\text { (mg) }\end{array}$ & $\begin{array}{l}\text { Dexpanthol } \\
\text { (mg) }\end{array}$ & $\begin{array}{l}\text { E } \\
\text { (mg) }\end{array}$ & $\begin{array}{l}\text { Biotin } \\
(\mu \mathrm{g})\end{array}$ & $\begin{array}{l}\text { Folate } \\
\text { ( } \mu \mathrm{g})\end{array}$ & $\begin{array}{l}B_{12} \\
(\mu g)\end{array}$ & $\begin{array}{l}K \\
(\mu \mathrm{g})\end{array}$ \\
\hline RDA (/kg/day) & $15-25$ & $0.21-0.45$ & $1.7-4.3$ & $0.20-0.35$ & $0.15-0.20$ & $0.15-0.20$ & $4-6.8$ & $1-2$ & 3.5 & $5-8$ & 56 & 0.3 & 80 \\
\hline MVIP* (2 ml/kg/day) & 32 & 0.28 & 4 & 0.48 & 0.56 & 0.4 & 6.8 & 2 & 2.8 & 8 & 56 & 0.4 & 80 \\
\hline Solv/Vitlipt & 10 & 0.28 & 4 & 0.3 & 0.36 & 0.4 & 4 & 1.5 & 2.8 & 6 & 40 & 0.5 & 80 \\
\hline
\end{tabular}

\section{AA supplements}

Standard parenteral multivitamin supplementation was $1 \mathrm{ml} / \mathrm{kg} /$ day Soluvit N (Kabi Pharmacia AB, Stockholm, Sweden) plus $4 \mathrm{ml} / \mathrm{kg} /$ day Vitlipid N (Kabi Pharmacia AB), both added to Intralipid (Kabi Pharmacia $A B$ ), which provided $10 \mathrm{mg} / \mathrm{kg} /$ day $\mathrm{AA}$. While requiring parenteral nutrition, infants randomised to low AA received this standard multivitamin regimen, and infants randomised to a high regimen received the standard regimen plus an extra $20 \mathrm{mg} / \mathrm{kg} /$ day AA. The combination of Soluvit and Vitlipid ${ }^{18}$ was chosen because this regimen delivers comparable amounts of all vitamins to that delivered by $2 \mathrm{ml} / \mathrm{kg} /$ day MVI-Pediatric (Rhone-Poulenc Rorer, Montreal, Canada), ${ }^{19} 20$ except that the AA content is lower (table 1).

Our policy is to encourage enteral feeding with mother's own breast milk (assumed to contain $4.0 \mathrm{mg} / 100 \mathrm{ml} \mathrm{AA}$ ). Formula fed infants received S26 LBW formula (Wyeth, Auckland, New Zealand), which contains 11 mg/100 ml AA. S26 LBW powder (5 g/100 ml, containing $3.3 \mathrm{mg}$ AA) was used to fortify breast milk when required. Orally fed infants also received Vitadol C (Nutricia, Auckland, New Zealand), which contains $33 \mathrm{mg}$ AA in 10 drops $(0.3 \mathrm{ml})$. Table 2 shows feeding regimens for infants fed $150 \mathrm{ml} / \mathrm{kg} / \mathrm{day}$. Infants randomised to high AA (group $\mathrm{HH}$ and group LH from day 11 onwards) also received an additional $20 \mathrm{mg} / \mathrm{kg} / \mathrm{day}$ AA as a clear oral solution $(10 \mathrm{mg} / \mathrm{ml})$. Infants randomised to low AA (group LL and group LH to day 10) received sterile water as placebo. Both AA solution and placebo were dispensed as $2 \mathrm{ml} / \mathrm{kg}$ from a separate named bottle for each infant, marked "vitamin C or placebo".

\section{Measurement of AA and protein carbonyls}

Plasma AA concentrations were measured at study entry (usually day 2) and at day 10 (range 8-12), 21, and 28, on heparinised blood $(0.4 \mathrm{ml})$ collected at the time of routine sampling. Samples were stored at $4^{\circ} \mathrm{C}$ for no more than 30 minutes before the plasma was separated and frozen at $-80^{\circ} \mathrm{C}$. $\mathrm{AA}$, in the reduced form, was measured by high performance liquid chromatography (HPLC) using a C18 column with electrochemical detection. ${ }^{21}$ The detection limit was $1 \mu \mathrm{M}$, and the intra-assay coefficient of variation for plasma containing $60 \mu \mathrm{M}$ AA was $3.9 \%$. Protein carbonyls were measured on selected day 28 samples by an enzyme linked immunosorbent assay (ELISA) method that involves derivatising with 2,4-dinitrophenylhydrazine, ${ }^{22}$ using a commercial kit (Zenith Technology, Dunedin, New Zealand).

\section{Outcome measures}

Clinicians and laboratory staff remained blinded to treatment allocation throughout the trial. Perinatal and neonatal data, including the clinical risk index for babies (CRIB) score, ${ }^{23}$ were collected as part of an ongoing clinical audit. Primary outcomes were oxygen requirement at 28 days and 36 weeks postmenstrual age, total days supplemental oxygen, and ROP in infants eligible for screening. Supplemental oxygen was generally administered to infants unable to maintain a saturation of $95 \%$ or more in room air. ROP was assessed by an experienced paediatric ophthalmologist and reported using international criteria. ${ }^{24}$ Screening for ROP is routinely undertaken in New Zealand for infants of $<1250 \mathrm{~g}$ birth weight or $<31$ weeks gestation, and outside these limits at physician discretion. ${ }^{25}$

\section{Power calculations and statistical analysis}

Power calculations were conducted, using Monte Carlo simulation based on our preliminary study, ${ }^{17}$ for logistic regressions of major outcomes on AA concentrations, with adjustment for gestational age. They suggested that 120 patients would provide at least $80 \%$ power to detect a $40 \%$ reduction in risk for major outcomes - that is, a relative risk of 0.6 -assuming significance testing at the 5\% level.

Data were analysed in two ways. Firstly, conventional between group analysis by intention to treat was performed using $\chi^{2}$ tests, Fisher's exact test, or non-parametric analysis of variance (Kruskal-Wallis) as appropriate. Adjustment for covariate imbalance between the three treatment groups was achieved using a logistic regression model. Secondly, the association between AA concentrations, treated as a continuous variable, and binary outcomes was investigated with logistic regression models. Logistic regression models were used to estimate relative risks of morbidity (ROP, oxygen requirement at 28 days, and at 36 weeks postmenstrual age) comparing risk at optimal AA concentrations at different time points with risk at higher or lower concentrations.

\section{RESULTS}

A total of 119 infants, 40 in both LL and LH groups and 39 in the $\mathrm{HH}$ group, and $90 \%$ of those eligible, were enrolled over 24 months. The mean (SD) gestational age was 28.4

Table 2 Calculated average daily amounts of vitamins C, A, D, and E received by infants randomised to a low ascorbic acid (AA) regimen and fed $150 \mathrm{mg} / \mathrm{kg} /$ day. Infants randomised to high AA received an additional $20 \mathrm{mg} / \mathrm{kg} /$ day vitamin $C$

\begin{tabular}{|c|c|c|c|c|}
\hline & $C(\mathrm{mg})$ & $A(m g)$ & $D(\mu g)$ & $E$ (mg) \\
\hline EBM+5 drops/kg Vitadol C ${ }^{*}$ & 22.5 & 0.47 & 6.6 & 0.6 \\
\hline S26 LBW formula+3 drops $/ \mathrm{kg}$ Vitadol C & 26.4 & 0.37 & 5.8 & 2.4 \\
\hline $\mathrm{EBM}+5 \mathrm{~g} / 100 \mathrm{ml} \mathrm{S} 26+3 \mathrm{drops} / \mathrm{kg}$ Vitadol C & 20.4 & 0.32 & 4.3 & 1.4 \\
\hline
\end{tabular}

*Nutricia, Auckland, New Zealand.

EBM, Expressed breast milk. 
Table 3 Subject characteristics by study group

\begin{tabular}{|c|c|c|c|c|}
\hline & LL $(n=40)$ & LH $(n=40)$ & $\mathrm{HH}(n=39)$ & $\mathrm{p}$ Value \\
\hline $\begin{array}{l}\text { Maternal ethnicity } \\
\text { (European) }\end{array}$ & $34(85)$ & $37(93)$ & $34(87)$ & $0.60+$ \\
\hline \multicolumn{5}{|l|}{ Antenatal steroids } \\
\hline Full & $21(53)$ & $20(50)$ & $21(54)$ & $0.79 \dagger$ \\
\hline Partial & $13(33)$ & $17(42)$ & $13(33)$ & \\
\hline Chorioamnionitis (yes) & $5(12)$ & $3(8)$ & $3(8)$ & $0.79 \dagger$ \\
\hline Caesarean section & $29(73)$ & $25(63)$ & $21(54)$ & $0.23 \ddagger$ \\
\hline Male & $22(55)$ & $25(63)$ & $16(41)$ & $0.15 \ddagger$ \\
\hline $\begin{array}{l}\text { Hyaline membrane } \\
\text { disease }\end{array}$ & $34(85)$ & $29(73)$ & $29(74)$ & $0.36 \ddagger$ \\
\hline Ventilation - any & $31(78)$ & $27(68)$ & $25(64)$ & $0.40 \ddagger$ \\
\hline Surfactant (\% yes) & $29(73)$ & $24(60)$ & $26(67)$ & $0.50 \ddagger$ \\
\hline $\begin{array}{l}\text { Gestational age } \\
\text { (weeks)* }^{*}\end{array}$ & $27.9(27.2$ to 28.6$)$ & 28.6 (27.8 to 29.4 ) & 28.7 (27.8 to 29.6 ) & 0.29 ब \\
\hline Birth weight $(g)^{*}$ & 1109 (1007 to 1210 ) & 1181 (1065 to 1297) & 1175 (1051 to 1300$)$ & 0.75 \\
\hline CRIB score* & $2.30(1.43$ to 3.17$)$ & 2.15 (1.32 to 2.98$)$ & 2.28 (1.33 to 3.24$)$ & 0.95 \\
\hline \multicolumn{5}{|c|}{$\begin{array}{l}\text { Unless otherwise stated, values are number (\%). } \\
\text { *Values are mean ( } 95 \% \text { confidence interval). } \\
\text { tFisher's exact test. } \\
\pm \chi^{2} \text { test. } \\
\text { - Kruskal-Wallis test. }\end{array}$} \\
\hline
\end{tabular}

(2.5) weeks, birth weight 1161 (371) g, and CRIB 2.3 (2.7). There was no difference in birth weight, gestation, or CRIB score between groups, which were also well matched in other respects (table 3 ).

Six infants (5\%) died, one each on days $1,3,5,7,8$, and 9. One infant was in group LL, two in group LH, and three in group $\mathrm{HH}$. Their mean CRIB score was $5.2(\mathrm{n}=5$; missing data for one infant). These six infants had significantly higher AA concentrations before randomisation (day 2) than the 111 surviving infants $(116 \mu \mathrm{mol} / \mathrm{l}$ (95\% CI 90 to 142$) v$ $51 \mu \mathrm{mol} / \mathrm{l}(95 \% \mathrm{CI} 45$ to 58$), \mathrm{p}<0.0001)$. The odds ratio (OR) for risk of death corresponding to a $35 \mu \mathrm{mol} / \mathrm{l}$ (approximately $1 \mathrm{SD}$ ) increase in AA concentration before randomisation was 5.21 (95\% CI 2.16 to 19.23), and this estimate changed little after adjustment for gestational age and CRIB score (OR 5.26 (95\% CI 2.15 to 20.83)).

Table 4 shows the relations between group assignment, AA concentrations, and primary and other clinical outcomes. Based on logistic regression modelling, there was no significant difference between groups with respect to AA concentrations before randomisation (day 2), but differences on days 10, 21, and 28 were highly significant and in the direction predicted (fig 1). There were no significant differences in primary outcomes between the groups, although the proportion of surviving infants with an oxygen requirement at 36 weeks postmenstrual age in group $\mathrm{HH}$ $(19 \%)$ was half that in group LL $(41 \%)$. When the analysis was restricted to these two groups, this difference approached significance $(p=0.06)$. Adjusting data for gestational age and CRIB score, using logistic regression, did not alter the between group differences substantially (table 5), with the standardised proportion of surviving infants with an oxygen requirement at 36 weeks postmenstrual age in group $\mathrm{HH}$ $(16 \%)$ remaining half that in group LL $(36 \%)(p=0.06)$. There were no significant differences between groups for other outcomes.

Logistic regression analyses at each time point for oxygen requirement at 28 days and 36 weeks, and ROP showed no significant relations with AA concentration after adjustment for gestational age and CRIB score (table 6).

To assess whether high AA concentrations could have a pro-oxidant effect, we measured protein carbonyls as an index of protein oxidation in a subset of plasma samples.
We selected two groups of day 28 samples, those with $\mathrm{AA}$ concentrations $\leqslant 50 \mu \mathrm{mol} / \mathrm{l}(\mathrm{n}=30$; mean $(\mathrm{SD}) 31$ (12) $\mu \mathrm{mol} / \mathrm{l}$ ) and those with AA concentrations $\geqslant 80 \mu \mathrm{mol} / \mathrm{l}$ ( $\mathrm{n}=27 ; 103(29) \mu \mathrm{mol} / \mathrm{l})$. The low AA samples had a mean protein carbonyl concentration of 0.133 (0.071) nmol/mg compared with $0.126(0.059) \mathrm{nmol} / \mathrm{mg}$ for the high AA samples; these values were not significantly different.

\section{DISCUSSION}

We hypothesised that having lower AA concentrations in the first week of life (target 35-50 $\mu \mathrm{mol} / \mathrm{l}$ ) and higher concentrations in weeks 3-4 (target $90 \mu \mathrm{mol} / \mathrm{l}$ ) would decrease morbidity (chronic lung disease and ROP) in very low birthweight infants. Therefore we designed the study with three groups, one aiming to keep AA concentrations low throughout (LL), one with high concentrations throughout $(\mathrm{HH})$, and a group crossing over from low initially to high at day 10 (LH). Although we achieved significantly different AA concentrations at days 10,21, and 28 between the groups in the direction expected, there were no significant differences in primary outcomes. The results did show trends towards better respiratory outcome being associated with higher AA intake, and it is a possibility that by distributing infants in

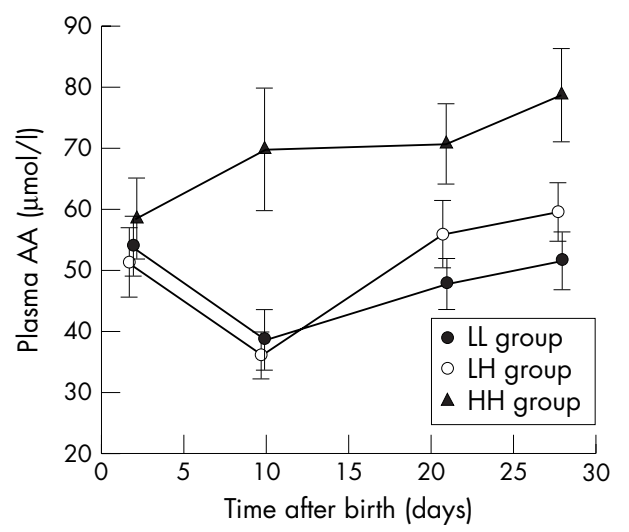

Figure 1 Plasma ascorbic acid (AA) concentrations (mean (SD)) for the group who received low AA supplementation throughout (LL), the group who received low AA until day 10 and then high (LH), and the group who received high AA throughout $(\mathrm{HH})$ at the different time points. 





Table 5 Outcome rates standardised for gestational age and CRIB score

\begin{tabular}{|c|c|c|c|c|}
\hline & LL & LH & $\mathrm{HH}$ & p Value \\
\hline Oxygen at 28 days & 49 (31 to 67) & 34 (18 to 55$)$ & 38 (7 to 35$)$ & 0.28 \\
\hline Oxygen at 36 weeks PMA & 36 (22 to 55$)$ & 24 (11 to 42$)$ & $16(21$ to 59$)$ & 0.06 \\
\hline ROP & 30 (14 to 53$)$ & $34(15$ to 59$)$ & 32 (15 to 57$)$ & 0.78 \\
\hline
\end{tabular}

Table 6 Odds ratios and $95 \%$ confidence intervals for oxygen requirement a 28 days and 36 weeks postgestational age, and retinopathy of prematurity (ROP), related to plasma ascorbic acid concentrations ( 30 unit increases) after adjustment for gestational age and CRIB score by logistic regression and at each time point

\begin{tabular}{|c|c|c|c|c|c|c|}
\hline \multirow[b]{2}{*}{ Day } & \multicolumn{2}{|c|}{ Oxygen at 28 days } & \multicolumn{2}{|c|}{ Oxygen at 36 weeks } & \multicolumn{2}{|l|}{ ROP } \\
\hline & $\overline{\mathrm{OR}}$ & $95 \% \mathrm{Cl}$ & $\overline{\mathrm{OR}}$ & $95 \% \mathrm{Cl}$ & $\overline{\mathrm{OR}}$ & $95 \% \mathrm{Cl}$ \\
\hline 2 & 0.685 & 0.421 to 1.117 & 0.840 & 0.530 to 1.330 & 0.859 & 0.458 to 1.1612 \\
\hline 10 & 0.982 & 0.511 to 1.887 & 0.890 & 0.536 to 1.447 & 1.162 & 0.662 to 2.037 \\
\hline 21 & 1.693 & 0.893 to 3.209 & 0.866 & 0.449 to 1.669 & 1.211 & 0.567 to 2.586 \\
\hline 28 & 1.124 & 0.495 to 2.550 & 1.067 & 0.541 to 2.108 & 0.650 & 0.219 to 1.930 \\
\hline
\end{tabular}

three groups, the study lacked sufficient power to detect a difference. Comparing only the LL and HH groups, the mean requirement for oxygen at 36 weeks was twice as high in the low intake group. Most would consider this difference clinically significant and it approached statistical significance $(p=0.06)$, as did comparisons across the three groups with the data corrected for gestation and CRIB score (table $5, \mathrm{p}=$ 0.06 ). We must be cautious in attributing any advantage to the high dose AA, as there was no relation between AA concentrations at any time point and outcome measures. However, there was no evidence that the high dose AA was harmful, and the results suggest that supplementing very preterm infants at this higher AA concentration may be beneficial.

One possible limitation is that AA concentrations in the high groups did not reach our target range. This target was based on our preliminary observational study where the mean AA concentration at 28 days for infants without bronchopulmonary dysplasia was $93 \mu \mathrm{mol} / \mathrm{l}$. During that study, infants who were fed parenterally received $25 \mathrm{mg} / \mathrm{kg} /$ day AA from $2 \mathrm{ml} / \mathrm{kg} /$ day MVIP given over six hours. ${ }^{26}$ However, the time of plasma sampling was not standardised, and some high AA concentrations may have resulted from sampling during the MVIP infusion. In the present study infants received the multivitamins infused over 24 hours.

Infants randomised to our high regimen received $30 \mathrm{mg} /$ $\mathrm{kg} /$ day AA while on parenteral nutrition and $40-46 \mathrm{mg} / \mathrm{kg} /$ day when fed enterally, compared with an expert committee's recommended daily dose of $25-31 \mathrm{mg} / \mathrm{kg} /$ day for preterm infants up to $3 \mathrm{~kg} .{ }^{10}$ Higher doses of AA have been given in earlier studies, but with no clinical outcomes reported..$^{27}$ Bass et al ${ }^{29}$ compared no supplementation with $100 \mathrm{mg} / \mathrm{kg} / \mathrm{day}$ AA in preterm infants during the first week of life and reported no differences in outcome. In the baboon model of bronchopulmonary dysplasia, ${ }^{30} 100 \mathrm{mg} / \mathrm{kg} /$ day AA in addition to the standard dose for 10 days raised plasma concentrations 10-fold to a mean $395 \mu \mathrm{mol} / \mathrm{l}$ but did not benefit respiratory variables.

Relative to these studies, our dosages of AA were cautious, but were selected against the background debate about the possibility that AA may have pro-oxidant as well anti-oxidant actions. $^{2}{ }^{31-33}$ Although there are reports that high dietary AA may have oxidant effects in adults, ${ }^{34}$ an extensive review concluded that such pro-oxidant activity was at best unproven under physiological conditions. ${ }^{3}$ In very low birthweight infants, the situation is more complex, as they are born with low transferrin concentrations, and tend to have high iron status through repeated transfusions. Non-transferrin bound iron has been detected in plasma of preterm infants by several groups. ${ }^{35-37}$ However, there was no evidence of increased lipid or protein oxidation associated with the presence of this iron and high AA concentrations. ${ }^{38}$ Together with our observation that protein oxidation was no different for high and low plasma AA concentrations, these results suggest that a pro-oxidant role of ascorbate at the doses we used is unlikely.

As in an earlier report, ${ }^{14}$ high AA concentrations in the first days of life were associated with an increased risk of dying. Whereas this report suggested that this may reflect harmful pro-oxidant effects of AA, other explanations are possible. Brain tissue is rich in ascorbic acid..$^{39}$ Arad and Eyal ${ }^{40}$ reported that preterm infants with an intraventricular haemorrhage had higher plasma AA concentrations on days 1-5 than infants without haemorrhage. Dvir et $a l^{41}$ reported that intrapartum fetal distress was associated with higher umbilical venous AA concentrations and speculated that a hypoxic insult releases AA into the circulation. Five of the six infants in our study who died had first week cranial ultrasound scans; four had bilateral intraventricular haemorrhage, plus intracerebral haemorrhage in one case, and one had widespread changes compatible with "anoxic brain injury". (Only two other infants had an intraventricular haemorrhage and one an intracerebral haemorrhage, their day 2 AA concentrations being 35, 87, and $59 \mu \mathrm{mol} / \mathrm{l}$ respectively.) Although these findings warrant further investigation, it seems probable that the high AA concentrations found in infants who died are more likely to be a marker of a significant cerebral insult than a contributor to the infant's demise per se.

In conclusion, in a blinded randomised controlled trial, we were able to achieve higher or lower AA concentrations at 10 , 21 , and 28 days of age. Treatment allocation was not associated with significantly improved outcome, although there was a trend towards less respiratory morbidity for infants randomised to receive higher AA supplementation throughout. With no evidence for any harmful pro-oxidant 
effects, we suggest it may be reasonable to provide at least this level of supplementation.

\section{ACKNOWLEDGEMENTS}

This work was supported by a project grant from the Health Research Council of New Zealand. F McG was the recipient of a Masonic Postgraduate Fellowship in Paediatrics and Child Health. We thank Nina Mogridge for help with data collection and Dug Yeo Han for help with statistical analysis. We are also very grateful to the nursing staff of the neonatal intensive care unit of Christchurch Women's Hospital and to the parents and families involved for their support for the study.

\section{Authors' affiliations}

B A Darlow, F McGill, Departments of Paediatrics, Christchurch School of Medicine, Christchurch, New Zealand

H Buss, C C Winterbourn, Department of Pathology, Christchurch School of Medicine

L Fletcher, P Graham, Public Health and General Practice, Christchurch School of Medicine

Competing interests: none declared

\section{REFERENCES}

1 Frei B, England L, Ames BN. Ascorbate is an outstanding antioxidant in human blood plasma. Proc Natl Acad Sci USA 1989;86:6377-81.

2 Halliwell B. Vitamin C: antioxidant or pro-oxidant in vivo? Free Radic Res 1996;25:439-54.

3 Carr A, Frei B. Does vitamin C act as a pro-oxidant under physiological conditions? FASEB J 1999;13:1007-24.

4 Proteggente AR, England TG, Rice-Evans CA, et al. Iron supplementation and oxidative damage to DNA in healthy individuals with high plasma ascorbate. Biochem Biophys Res Commun 2001;288:245-51.

5 Streeter ML, Rosso P. Transport mechanisms for ascorbic acid in the human placenta. Am J Clin Nutr 1981;34:1706-11.

6 Hamil BM, Munks B, Moyer EZ, et al. Vitamin C in the blood and urine of the newborn and in the cord and maternal blood. Am J Dis Child 1947;74:417-33.

7 Lindeman JHN, Van Zoeren-Grobben D, Schrijver J, et al. The total free radical trapping ability of cord blood plasma in preterm and term babies. Pediatr Res 1989;25:20-4

8 Berger TM, Rifai N, Avery ME, et al. Vitamin C in premature and full-term human neonates. Redox Rep 1996;2:257-62.

9 Nutrition Committee, Canadian Paediatric Society. Nutitrion needs and feeding of premature infants. Can Med Assoc J 1995;152:1765-85.

10 Greene HL, Smidt $U$. Water-soluble vitamins: $C, B_{1}, B_{2}, B_{6}$, niacin, pantothenic acid, and biotin. In: Tsang RC, Lucas A, Uauy R, et al, eds. Nutritional needs of the preterm infant. Baltimore: Williams and Wilkins, 1992: chapter 9.

11 Ingalls TH, Draper R, Teel HM. Vitamin C in human pregnancy and lactation. II. Studies during lactation. Am J Dis Child 1938;56:1011-19.

12 Moran LR, Vaughan R, Stroop S, et al. Concentrations and total daily output of micronutrients in breast milk of mothers delivering preterm: a longitudinal study. J Pediatr Gastroenterol Nutr 1983;2:629-34

13 Buss IH, McGill F, Darlow BA, et al. Vitamin C is reduced in human milk after storage. Acta Paediatr 2001;90:813-15.

14 Silvers KM, Gibson AT, Powers HJ. High plasma vitamin C concentrations at birth associated with low antioxidant status and poor outcome in premature infants. Arch Dis Child Fetal Neonatal Ed 1994;71:F40-4

15 Silvers KM, Gibson AT, Russell JM, et al. Antioxidant activity, packed cell transfusions, and outcome in premature infants. Arch Dis Child Fetal Neonatal Ed 1998;78:F124-9.
16 Moison RM, van Zoeren-Grobben D, Haasnoot AA, et al. Early biochemical detection of bronchopulmonary dysplasia (BPD) in preterm babies [abstract]. Pediatr Res 1995:37:343A.

17 Sluis KB, Inder T, Wilkinson A, et al. Plasma and endotracheal vitamin C concentrations in premature infants: relationship to outcome measures [abstact]. Proceedings of the 14th Annual Congress of the Australian Perinatal Society, 1996.

18 Roberton NRC. A manual of neonatal intensive care. London: Edward Arnold, 1992.

19 Crouch JB, Rubin LP. Nutrition. In: Cloherty JP, Stark AR, eds. Manual of neonatal care. Boston: Little Brown and Co, 1991.

20 Levy RL, Herzberg GR, Andrews WL, et al. Thiamine, riboflavin, folate, and vitamin $B_{12}$ status of low birth weight infants receiving parenteral and enteral nutrition. J Parenteral Enteral Nutr 1992;16:241-7.

21 Behrens WA, Madere R. A highly sensitive high-performance liquid chromatography method for the estimation of ascorbic and dehydroascorbic acid in tissues, biological fluids and foods. Anal Biochem 1987;165:102-7.

22 Buss IH, Chan TP, Sluis KB, et al. Protein carbonyl measurement by a sensitive ELISA method. Free Radic Biol Med 1997;23:361-6.

23 The International Neonatal Network. The CRIB (clinical risk index for babies) score: a tool for assessing initial neonatal risk and comparing performance of neonatal intensive care units. Lancet 1993;342:193-8.

24 International Committee for the Classification of Retinopathy of Prematurity. An international classification of retinopathy of prematurity. Arch Ophthalmol 1984; 102:1130-4

25 Darlow BA, Clemett RS. Retinopathy of prematurity; screening and optimal usage of the ophthalmologists time. Aust N Z J Ophthalmol 1990;18:41-6.

26 Inder TE, Carr AC, Winterbourn CC, et al. Vitamin A and E status in very low birth weight infants: development of an improved parenteral delivery system. J Pediatr 1995; 126:128-31.

27 Moore MC, Greene HL, Phillips B, et al. Evaluation of a pediatric multiple vitamin prparation for total parenteral nutrition in infants and children. 1. Blood levels of water-soluble vitamins. Pediatrics 1986;77:530-8.

28 Greene HL, Hambridge KM, Schanler R. Guidelines for the use of vitamins, trace elements, calcium, magnesium, and phosphorus in infants and children receiving total parenteral nutrition. Am J Clin Nutr 1988;48:1324-42.

29 Bass WT, Malati N, Castle MC, et al. Evidence for the safety of ascorbic acid administration to the premature infant. Am J Perinatol 1998;15:133-40.

30 Berger TM, Frei B, Rifai N, et al. Early high dose antioxidant vitamins do not prevent bronchopulmonary dysplasia in premature baboons exposed to prolonged hyperoxia: a pilot study. Pediatr Res 1998;43:719-26.

31 Bohles H. Antioxidative vitamins in prematurely and maturely born infants. Int J Vitam Nutr Res 1997;67:321-8.

32 Berger TM, Frei B. Pro- or antioxidant activity of vitamin $C$ in preterm infants? [Correspondence]. Arch Dis Child Fetal Neonatal Ed 1995;72:F211.

33 Powers HJ, Loban A, Silvers K, et al. Vitamin C at concentrations observed in premature babies inhibits the ferroxidase activity of caeruloplasmin. Free Radic Res 1995;22:57-65.

34 Podmore I, Griffiths HR, Herbert KE, et al. Vitamin C exhibits pro-oxidant properties. Nature 1998;392:559.

35 Ciccoli L, Rossi V, Leoncini S, et al. Iron release in erythrocytes and plasma non protein-bound iron in hypoxic and non hypoxic newborns. Free Radic Res 2003;37:51-8.

36 Evans PJ, Evans R, Kovar IZ, et al. Bleomycin-detectable iron in the plasma of premature and full term neonates. FEBS Lett 1992;303:210-12.

37 Kime R, Gibson A, Yong W, et al. Chromatographic method for the determination of non-transferrin-bound iron suitable for use on the plasma and bronchoalveolar lavage fluid of preterm babies. Clin Sci (Lond) 1996;91:633-8.

38 Berger TM, Polidori MC, Dabbagh A, et al. Antioxidant activity of vitamin C in iron-overloaded human plasma. J Biol Chem 1997;272:15656-60.

39 Rumsey SC, Levine M. Absorption, transport and distribution of ascorbic acid in humans. J Nutr Biochem 1998;9:116-30.

40 Arad ID, Eyal FG. High plasma ascorbic acid levels in premature neonates with intraventricular haemorrhage. Am J Dis Child 1983;137:949-51.

41 Dvir M, Kohelet D, Arbel E, et al. Umbilical ascorbic acid levels in fetal distress. J Nutr Sci Vitaminol 1992;38:511-15. 